\title{
An International Conversation about Mentored Undergraduate Research (and Inquiry) and Academic Development
}

Susan Larson, Lee Partridge, Helen Walkington, Brad Wuetherick, and Jessie L. Moore

Recognizing that regional differences in mentored undergraduate research and inquiry (URI) practices shape how academic developers might adapt international resources to their local contacts, guest editor Jessie L. Moore invited four scholars to discuss the key terms, concepts, and initiatives for mentored URI in their countries.

Susan Larson is a professor of psychology at Concordia College in Moorhead, Minnesota. She is a Councilor with the Council on Undergraduate Research and served as the 2016-2017 president of the US-based organization.

Lee Partridge is the founding director of University to Community Inc. in Perth, Australia; serves as an executive member of the Higher Education Research and Development Society of Australasia; and is an associate professor and academic developer at the University of Western Australia.

Helen Walkington is a professor of higher education in the Department of Social Sciences at Oxford Brookes University in Oxford, UK. She is a National Teaching Fellow and has been a steering group member of the British Conference of Undergraduate Research (BCUR) since its inception in 2010.

Brad Wuetherick is Executive Director of the Centre for Learning and Teaching at Dalhousie University in Halifax, Nova Scotia, Canada. He previously served as a Canadian Vice President on the Board of Directors for the International Society for the Scholarship of Teaching and Learning.

Jessie L. Moore is Director of the Center for Engaged Learning at Elon University, which sponsored a 2014-2016 multi-institutional and international research seminar on excellence in mentoring undergraduate research.

\section{Regional Characteristics of Undergraduate Research and Inquiry}

Jessie L. Moore: What does undergraduate research and inquiry (URI) look like in different regions? What characteristics of URI are critical in your region?

Susan Larson: Thinking broadly across the US context, it depends on the kind of institution. At smaller, private institutions, a critical component is that intensive one-on-one URI, or onementor-with-a-small-group-of-students URI, tends to happen in the summer. At larger institutions, it might happen during the school year, but it may be mentored by graduate students and post-docs. 
Helen Walkington: The UK has a slightly more embedded model of undergraduate research and inquiry because all of our students are doing dissertations and honours degrees, so there's an expectation that they all will be doing research and that the research will be supervised. We have some instances of URI outside the curriculum, but the general focus on URI is more institutionalized, it's more embedded in the curriculum, and it's an expectation in the final year that students will be doing research on a one-to-one basis with a dissertation supervisor. In some cases that supervisory relationship bleeds into mentoring, and there isn't a hard and fast rule of when it's supervising and when it's mentoring, so it leads to a slightly different terminology than in other contexts. We use 'students as researchers' or 'students as producers', so it's a very student-focused way of identifying students doing research, and they tend to be in mentored relationships with academic staff.

Lee Partridge: Undergraduate research is not embedded in the Australian higher education sector. There are good examples of it here and there, but it's not an expectation unless you were doing Honours, and not all undergrads go on to an Honours year. There are some shining lights of URI in the Australian system; Angela Brew has worked very hard to establish the Australian version of CUR. They have an annual conference, and the vast majority of students presenting there are Honours students. There are summer opportunities for URI, but almost exclusively in the STEM areas and not wide-spread. Only a select few students would do summer URI.

Brad Wuetherick: Canada has a long-standing tradition of funding summer mentored undergraduate research, though few of our institutions have formal undergraduate research offices. URI offices are becoming more common, and many institutions are investing additional funding for URI in disciplines that have limited access to federal funding or in disciplines that draw high numbers of underrepresented communities (e.g., indigenous students, women in science, etc.). Canada is fairly far along in terms of formalizing URI as part of curriculum, so there's a lot of work on curriculum-based undergraduate research. There also are ongoing conversations about whether teaching is a mentoring relationship.

\section{Supervisors vs Mentors}

Moore: You have used different terms - supervising and mentoring - to describe the academic staff and student URI relationship in your regions. How do you understand the differences between those terms?

Walkington (UK): With "mentoring" as I understand it in the North American sense, mentoring goes beyond just an academic relationship. It might be that mentors take a broader interest in the student regarding their identity development and their careers following the university. Within the UK, there are many supervisors who would foster that mentoring relationship, but there are just as many who wouldn't extend past the supervisory role. For them, the supervisory role is clearly professional, not personal. 
Larson: I think the personal versus professional relationship varies quite a bit within the US system. Sometimes mentors develop deep relationships with their URI students; other times, the boundaries maintain a more professional relationship.

Partridge: "Mentoring" isn't used at all. We use "supervising" rather than "mentoring," and it tends to be a version of people's experience supervising post-graduate students. Supervisors generally haven't considered how supervising needs might vary for undergraduates so it's more of a sort of bleeding of the post-graduate experience into the undergraduate sector, rather than a specific set of strategies for the undergraduate student group.

Wuetherick: In Canada, historically, people have used supervision and mentoring interchangeably. A lot of campuses would say they do a lot of active mentorship for undergraduate students, when in reality what they are doing is more supervision, but there is emerging work exploring what mentorship models might look like when working with undergraduate students. In Canada, there's been a lot of work on what mentoring looks like in clinical internships and co-op placements and those kinds of things, as well as peer mentoring. So, there's been a lot of mentoring work done in Canada, though not exclusively within the sphere of undergraduate research. A lot of that mentoring discussion is informed by what happens in graduate and post-doc mentoring.

\section{Undergraduate Research and Inquiry as a Retention Initiative}

Larson: Mentoring URI in the early periods of undergraduate education, in year one or two, has seen more focus in the US as a retention initiative. There may be a different philosophy of mentoring when you are mentoring with the goal of helping to retain students rather than mentoring a senior year honors experience.

Walkington: In the UK, we're beginning to think that students might not be sufficiently prepared for their undergraduate research in their Honours year, so we're beginning to embed URI more and more in the early years of the curriculum. Students are starting to identify as researchers much earlier. We don't use URI as a tool for retention, though, because everyone is doing it. It isn't seen as an enrichment activity or as an optional extra. As a result, literature on the benefits for specific groups of learners is largely coming from the US. We do have a widespread problem in the UK of an attainment gap for students who are from minority ethnic groups, who are not coming out of the university in their final year with the equivalent grades to traditional groups, but universities haven't identified URI as an area we could use to address that in the same way that it's identified in the US. The benefits of URI are hidden in the UK, so maybe there's something going on with the mentoring - or lack of mentoring - of particular groups of students and this continuum between supervision and mentoring is actually not helping some people. Perhaps the supervising-mentoring continuum is really helping enrich the experiences of students who were doing well anyway, and those students are getting something approximating mentoring, on a case-by-case basis, that differs from the supervision 
students who are struggling receive, because it's all driven by the student. The student comes to see the academic member of staff; there aren't formal timetable sessions. The student must take the initiative to come see you.

Wuetherick: URI as a retention initiative also happens in Canada, but there is a movement towards systematically ensuring all undergraduate students experience research. In many Canadian contexts, students are experiencing URI embedded within the curriculum, where they may not be encountering the same kind of mentoring as the enrichment-oriented experiences. Course-embedded URI informs conversations about whether teaching is mentoring and how academic staff or faculty actually incorporate mentorship as an aspect of teaching. Part of my work over the last ten years centered on what we have learned about excellence in mentoring; if we don't bring what we know about mentoring into the course-based URI experiences, we may not be getting the most out of it for all students. Even in programs where all students participate in URI, there are still attainment gaps for marginalized communities. I don't think people understand the socio-cultural environment students are coming from as an aspect of mentorship, so they're treating all their students the same way rather than adapting for students' specific needs, including students' additional support needs.

\section{Characteristics of Mentored URI Across Institution Types and Disciplines}

Wuetherick: In Canada, there's a big distinction between what mentored URI looks like at the research universities versus what mentored URI looks like at the more undergraduate-focused universities. At research universities, faculty are relying on graduate students to do a lot of the mentoring of undergraduate student projects.

Walkington (UK): Are the graduate students trained to be mentors? Some universities in the US have quite well-developed training schemes for graduate students who are mentors, but I'm not expecting that happens everywhere.

Wuetherick: We have strong graduate student enrichment programs exploring teaching and mentoring in Canada, but the programs aren't mandatory, and only a small portion of students are taking them up.

Larson: In the US, the kinds of mentoring vary by the mission of the institution. If it's a teachingfocused institution where you are really looking to develop students through that undergraduate experience, then mentoring looks quite different than it does at research institutions, where a lot of mentoring might be done by post-docs and graduate students. Institution type also may lead to distinctions between the sciences and non-sciences. At the research institutions, there may be structured ways to bring undergraduates into the science research experience, and that may be less true in the humanities or some of the other fields where you don't have labs and you don't need a team of students to help you collect data. We also see that the structure that exists in a research institution may be more focused on the science, or specifically lab science, type experiences. 
Walkington: The distinction between science and non-science is less clear in the UK than in the US. In the UK, we don't really have the concept of the teaching institution, so while the amount of time available for teaching or research might vary for academic staff, from the student perspective, you don't think, "I'm at a teaching university," or "I'm at a research university." In terms of being a student as researcher or a student as producer, I think students come in with an expectation that they will do research regardless of the discipline they are in. Even if they are studying law, or other disciplines where professional bodies are filling the curriculum with things that have to be done by the time they've graduated to qualify as a professional, those students are still going to engage in research. Now the question is, does it count as research? The students think it counts as research; they're doing a dissertation, they're doing a final thesis, they're producing new ideas and material, but they're not creating a new law. It depends where we draw that distinction about what counts as research; is it something that's new to the student, or is it something that is genuinely new?

Walkington: I noticed, Jessie, that you used the term "undergraduate research and inquiry." There's also in North America "creative works," so art students might be less inclined to call themselves researchers and more inclined to call themselves producers. So, the idea of production of knowledge is an inclusive term, regardless of discipline. So, I don't think we have that strong difference between science and non-science in the UK, but like Susan says about the US, there are certain infrastructures that go with science in terms of laboratories and things like that, and graduate students and technicians working in laboratories are engaging with undergraduate students.

\section{Academic Development in Support of Academic Staff/Faculty Mentoring}

Jessie: What should academic developers be aware of as they are helping faculty become better mentors or supervisors?

Walkington: I think that academic developers should have a sense of the types of research going on in different disciplines. They are in a unique position usually in that they sit centrally and they're not dedicated only to one discipline or another, so they're in a brilliant position to share the different types of practice that go on across different disciplines. Mentoring might have a particular model in the sciences, and some of that group learning and partnering with graduate students might be really applicable to historians mentoring URI in the archives and things like that, but it's not something you would naturally think about. So, a brilliant contribution academic developers could make is to have a broad knowledge across different disciplinary types in terms of what counts as research in those disciplines and how to support research as a mentor. Faculty, or academic staff, have high turnover, with new people coming in all the time who haven't necessarily experienced being a producer of knowledge when they were a student at university. So, having academic developers with broad knowledge who can contribute that perspective is key. 
Wuetherick: I agree a lot with that cross-disciplinary lens that academic developers can use. When you think about undergraduate research, a lot of people will think about it in terms of the teaching of undergraduate research skills or as undergraduate research as a teaching strategy. People will think of it as supervising projects. But this idea of a continuum of teaching, supervision, and mentorship is something that academic developers really need to get their head around - that faculty need to be moving among those different positions regularly when they're working with undergraduate students, whether that's in one-on-one mentoring like summer experiences or curriculum-based UR experiences. There are times when faculty are going to be teaching, there will be times when they will be supervising, and there are times when they need to be a mentor.

Wuetherick: Academic developers also can help faculty understand that a core part of the mentoring relationship is supporting the students' own identity development. I think most faculty quite intuitively understand that students are developing their own research identity or academic identity or disciplinary identity. What they're probably less understanding about and less comfortable with is the other aspects of identity that are wrapped into the mentoring relationship. Students are coming with social, cultural, or personal identity components that may require faculty to take a different approach to mentorship than they might with another student. The student who is first in family or coming from a low socioeconomic background or coming from a historically disadvantaged community may have less social capital, so the mentor needs to help in a different way than they would with those students whose parents are professors or students who come from privilege. So, academic developers can help faculty explore the ideas that mentorship and identity development for students are entwined and that identity development is more than just the academic-researcher identity. A lot of faculty are uncomfortable sometimes navigating relationships with students that attend to students' other identity components. Brad Johnson's (2016) work on mentoring offers some strategies that academic developers could explore with faculty.

Partridge: Reflecting what Brad said, academic developers can help faculty get to know their students, which is a measure of good teaching, but even more so in the context of mentored URI. Because of students' stage of development, mentored URI is not just about transferring the skills you would use with graduate students to a younger age group; there's more to it than that. Knowing what their needs are as a group and as individuals is critical. Particularly in the humanities and social science areas, students have to start thinking differently, and they don't understand that at first. Academic developers can help mentors become conscious of the fact that it takes students a while to think differently, to think from a disciplinary, research perspective.

Larson: I'm less optimistic that faculty even think about their students' identities as researchers as much as they perhaps ought to, so sometimes I think just the notion of any kind of identity development is something that - for some faculty - they only begin to understand years into mentoring URI. So, for early career faculty, academic development on identity development in any area would be helpful. 
Larson: Academic developers also can help faculty consider how to work with students to understand what the project goals are. If the project really is about knowledge generation, there are certain goals faculty and undergraduate researchers have to accomplish. But if the goals extend beyond knowledge generation, how might faculty work with students to identify those goals? What are the other types of outcomes the students will experience that extend beyond the project topic? Academic developers can help faculty develop strategies for goal setting with students that is project-specific and goal setting that extends beyond the project, including identity development goals.

Wuetherick: Now you're asking the faculty members to think about learning outcomes!

Larson: It's easy to bring students in and to focus on the five things they'll get out of the project that are focused to better skills on library research or improved writing or concrete, researchrelated skills. But even then, there's work that could be done to help faculty articulate what those outcomes really are. Related to that, there's something important about helping to set expectations, framing the time commitment, discussing expectations for authorship, and giving faculty some tools to enter into those conversations early in projects - particularly projects that fall outside of the curricula. In the US, the classroom syllabus is this detailed contractual obligation we have with students, so when URI is embedded in the curriculum, I think expectations do get laid out pretty well, but when URI isn't embedded, that's when some work can be done by academic developers to help articulate expectations.

Partridge: Academic developers can help faculty articulate their definitions of what research is, making those understandings more obvious and overt to students. What does it mean to do research and what does that research look like? It's not just about the skills. It is thinking like a researcher and what that means and being able to identify the transferable skills that come out of that experience.

Wuetherick: I think faculty often underestimate what students are capable of. I love the work on students as producers and students as co-inquirers. I think a lot of faculty don't think students are capable of being partners or co-producers, so we have a lot of work to do in that realm. Academic developers need to work with faculty to understand that students, even at the first-year undergraduate level, are capable; they may need different types of support, and they are at a different level of development than a doctoral student, but they are capable.

Moore: That's a helpful reminder. We sometimes underestimate what students can do and the strengths that they bring both from their prior coursework and from their other experiences outside of academia.

Walkington: My research team from the Center for Engaged Learning's seminar on excellence in mentoring undergraduate research looked at mentoring practices across 30 different awardwinning mentors in our four countries, and one of the ten salient practices we identified is having high expectations of students (Shanahan et al., 2015). The entire list of ten salient practices we identified would be relevant to academic developers working with mentors, but 
having high-expectations of students is particularly relevant to this conversation. Academic staff often have a career trajectory that focuses initially on getting their own work published and then in later stages of their careers moves much more into mentoring. If academic developers have an awareness of the ten salient practices research, they could use that knowledge to inform activities with new or mid-career members of academic staff to revitalize their interest in working with students, especially if academic staff are coming back into teaching after focusing on big research projects.

Larson: One of the other things that I would add is that in the US, when we talk about integrating research into the curriculum, faculty often ask what they must give up in order to make room for research. What's content versus skill-building? How do you find a balance? Academic developers can help faculty reimagine curricula to consider how you both change course designs in core ways to integrate URI and still meet your course objectives. Or how do you change an entire course of study to really integrate research into the curriculum while still meeting the content needs of the major? Academic developers can contribute to enhancing URI if faculty feel more empowered to, capable of, and excited about reimagining curricula.

Walkington: I think that's not just relevant to the US, but that's an international point. Curriculum design is a key role for academic developers. That also gets around the challenge of key mentors leaving the university; if mentored URI is integrated in the curriculum, then people come in expecting to do it, so it becomes much more of an embedded student entitlement, rather than hit or miss depending on if you have a key academic staff member doing it.

Walkington: One of the other things academic developers have done in our institution is be proactively involved in sharing undergraduate research. They've been brilliant about supporting initiatives to bring students together in conferences. They have unbiased views across the institution, so they aren't favoring students from a specific disciplinary area. Academic developers can help bring together multi-disciplinary conferences because they have the skills necessary to work across teams of people. People working in the silos of their disciplines don't necessarily know who to contact in other areas of the university, but academic developers have the skills and contacts to bring those events and groups together.

Wuetherick: Academic developers also are increasing playing roles in shaping institutional policy frameworks. They might inform discussions shaping the research ethics processes around undergraduate research: How do we actually help streamline those process to make them less of a barrier to embedding URI in courses or to mentoring URI outside of courses? How do we actually recognize things like mentoring as part of tenure and promotion processes? Those are all things that academic developers can take a role in influencing within an institution. In IJAD, there's a lot of discussion of that upward facing role that academic developers are continuously playing - the macro level of the institution - and there are things to be done around URI in the institution at that level as well.

\section{Affordances of Mentored URI for Students and Faculty}


Moore: What else would you like academic developers to know about the affordances or benefits of mentored URI?

Wuetherick: The thing that has influenced my choice to stay working in undergraduate research for as long as I have is my fundamental belief, and the evidence corroborates this, that URI can be extremely transformational for students. It is one most impactful experiences when it comes to student development as learners, to shaping their identity, and to transferable skills. The outcomes that come from URI experiences touch on all aspects of academic work; URI improves writing, critical thinking, reasoning, and all sorts of things that spill over into other aspects of academic work. There's also evidence now, though most of it might be in the US, that undergraduate students who experience URI early in their careers are retained better, more successful in their academic careers, and more likely to go on to graduate study - all the kinds of things that universities and academics should care about. URI is one of those experiences that deeply matters. There's a lot of things that academic developers can pay attention to in the higher education landscape; I think URI needs to be one of them.

Larson: I would add to that list the benefits that faculty themselves can gain. Unfortunately, we have less clear data about faculty benefits, but the benefits to an individual professional's life include: help with data collection, setting up publication opportunities; more rewarding teaching; and more rewarding engagement with students. At institutions in the US, there are lots of questions about limited availability of time and money, but thinking about faculty benefits helps academic developers respond to those time and resource concerns.

Partridge: I agree with what everybody has said. While there are differences between our jurisdictions, the benefits of URI are universal across the board.

\section{References}

Johnson, W. B. (2016). On being a mentor: A guide for higher education faculty (2 ${ }^{\text {nd }}$ ed.). New York: Routledge.

Shanahan, J. O., Ackley-Holbrook E., Hall E., Stewart K., Walkington H. (2015). Ten salient practices of undergraduate research mentors: A review of the literature. Mentoring \& Tutoring: Partnership in Learning, 23(5), 359-376. 